OPEN ACCESS

Edited by: Xiangming He,

Tsinghua University, China

Reviewed by:

Juchen Guo,

University of California,

Riverside, United States

Chuan Wu,

Beijing Institute of Technology, China

Chunming Zhang,

National Center for Nanoscience and Technology (CAS), China

Shaomao Xu,

University of Maryland,

College Park, United States

*Correspondence:

Jian Liu

jian.liu@ubc.ca

Specialty section:

This article was submitted

to Energy Storage,

a section of the journal

Frontiers in Energy Research

Received: 06 December 2017

Accepted: 22 February 2018

Published: 12 March 2018

Citation:

Liu J, Zhu H and Shiraz MHA (2018) Toward 3D Solid-State Batteries via Atomic Layer Deposition Approach.

Front. Energy Res. 6:10.

doi: 10.3389/fenrg.2018.00010

\section{Toward 3D Solid-State Batteries via Atomic Layer Deposition Approach}

\author{
Jian Liu*, Hongzheng Zhu and Mohammad H. A. Shiraz \\ School of Engineering, Faculty of Applied Science, University of British Columbia, Kelowna, BC, Canada
}

3D solid-state batteries are receiving great attentions as on-board power supply systems for small-dimension devices, due to their high power and energy densities. However, the fabrication of 3D solid-state batteries has been a formidable challenge due to the limitation of conventional thin-film techniques. Recently, atomic layer deposition (ALD) has emerged as a powerful approach toward 3D solid-state batteries, because of its exclusive advantage of coating uniform, pinhole-free, and conformal functional thin films on high-aspect-ratio substrates. Herein, we review the most recent progress in the utilization of ALD for fabricating 3D solid-state batteries. Specifically, two aspects will be highlighted: the development of glassy solid-state electrolytes (especially lithium phosphorus oxynitride), and the fabrication of 3D solid-state batteries in half-cell and full-cell configurations via ALD approach. Based on this, the perspectives for further research will be discussed.

Keywords: 3D solid-state battery, solid-state electrolyte, atomic layer deposition, lithium phosphorus oxynitride, surface chemistry

\section{INTRODUCTION}

Solid-state thin-film batteries have been considered as promising technologies for powering a wide variety of small-dimension devices, such as microelectronics, medical implants, smart cards, and radio-frequency identification tags, due to their intrinsic safety and great flexibility in device design and integration (Long et al., 2004; Roberts et al., 2011). Early research have been focused on $2 \mathrm{D}$ solid-state batteries, which offered high power density owing to the fast $\mathrm{Li}$ ion and electron transport in thin films (Bates et al., 2000). However, 2D solid-state batteries have limitation in meeting growing demand for a higher energy density $\left(\mathrm{mAh} \mathrm{cm}^{-2}\right)$ from small-dimension devices. One approach to increase the energy density of $2 \mathrm{D}$ solid-state batteries is to increase the thickness of electrode thin films, which, however, will compromise battery power density because of the increased diffusion length for $\mathrm{Li}$ ions and electrons. One solution is switching from $2 \mathrm{D}$ to $3 \mathrm{D}$ solid-state batteries, which are structured on 3D substrates with high aspect ratio instead of planar substrates. 3D solid-state batteries will vastly improve both the energy and power densities, due to the significantly increased electrode area and maintained small thin-film thickness to insure fast Li ion and electron transport (Long et al., 2004; Oudenhoven et al., 2011; Roberts et al., 2011). Therefore, $3 \mathrm{D}$ solid-state batteries have been widely studied as the next-generation thin-film batteries in the past years.

Although several 3D solid-state battery configurations have been proposed, the fabrication of 3D solid-state batteries is challenging, due to the limitation of conventional thin-film techniques (such as physical vapor deposition, sputtering) (Oudenhoven et al., 2011; Roberts et al., 2011). 3D solid-state batteries require the step-wise deposition of conformal and pinhole-free functional thin films, including conductive layers, cathode, solid-state electrolyte (SSE), and anode, into 3D substrates. Atomic layer deposition (ALD) has emerged as a promising technique for 3D battery 
fabrication, because it can deposit high-quality thin films into $3 \mathrm{D}$ substrates. ALD utilizes a unique saturated and self-limiting reaction mechanism, which allows the deposition of a monolayer per ALD cycle (George, 2010). More importantly, ALD has been proven very effective in realizing conformal films in high-aspectratio substrates (Cheah et al., 2009; Liu et al., 2013). Therefore, enormous efforts have been devoted to developing the anode, cathode, and SSE materials by ALD, which are functional components for building 3D solid-state batteries. These materials, along with their ALD chemistry and processes have been summarized in several recent review papers (Knoops et al., 2012; Liu and Sun, 2015; Lu et al., 2017). This Mini Review is intended to be a highlight of recent breakthroughs in key material development by ALD and their applications in the integration of $3 \mathrm{D}$ solid-state battery devices. It is expected that this Review will shine lights on the future directions of material development and device design for $3 \mathrm{D}$ solid-state microbatteries by the ALD approach.

\section{SSEs BY ALD}

Fabrication of $3 \mathrm{D}$ batteries first requires the establishment of feasible ALD chemistry and processes for the anode, SSE, and cathode. Many anode (such as $\mathrm{TiO}_{2}, \mathrm{SnO}_{2}, \mathrm{Co}_{3} \mathrm{O}_{4}$, and $\mathrm{GaS}$ ) and cathode (such as $\mathrm{V}_{2} \mathrm{O}_{5}, \mathrm{LiCoO}_{2}, \mathrm{LiFePO}_{4}$, and $\mathrm{LiMnO}_{2}$ ) materials have been developed by ALD, and demonstrated good electrochemical performance in Li-ion batteries (Liu and Sun, 2015; Lu et al., 2017). Nevertheless, these anode and cathode are yet to be integrated into 3D solid-state batteries, and the lack of suitable SSEs by ALD becomes a limiting factor.

For the SSEs fabricated by ALD, they should possess the properties as required for all SSEs, such as high ionic conductivity, low electronic conductivity, good chemical stability, wide electrochemical window, and free from pine holes (Long et al., 2004). In addition, the SSEs by ALD need meet the following criteria in order to be used in 3D solid-state batteries. (1) Functional at the as-deposited state and without any harsh post treatment in order to preserve the continuity of the thin films (Liu et al., 2013; Kazyak et al., 2017). (2) ALD process should avoid complicated surface chemistry. By applying these criteria, the options for the SSEs by ALD are narrowed down to glassy inorganic SSEs (Liu et al., 2013; Cao et al., 2014).

Many glassy inorganic SSEs, such as $\mathrm{LiAlO}_{x}, \mathrm{Li}_{3} \mathrm{PO}_{4}, \mathrm{Li}_{2} \mathrm{SiO}_{3}$, $\mathrm{Li}_{5.1} \mathrm{TaO}_{z}, \mathrm{Li}_{x} \mathrm{Al}_{y} \mathrm{~S}$, and $\mathrm{LiAlF}_{4}$, have been deposited by ALD using a "sub-cycle" strategy (Liu and Sun, 2015; Cao et al., 2016; Xie et al., 2017). The sub-cycle strategy combines two or more ALD sub-cycles, and is thus advantageous for controlling the composition of SSEs by adjusting the ratio between different ALD sub-cycles. However, it also introduces relatively complex ALD chemistry and processes, which could add additional complication to the fabrication of 3D solid-state batteries. Therefore, SSEs with simpler ALD process and higher ionic conductivity are in great need.

Recently, exciting breakthrough has been made by several groups to develop ALD processes for lithium phosphorus oxynitride (LiPON), which is a highly ion-conducting glassy electrolyte widely adopted in 2D thin-film batteries (Cao et al., 2014). LiPON was deposited in a temperature range of $200-500^{\circ} \mathrm{C}$ by using several ALD processes, such as [lithium tert-butoxide $\left.\left(\mathrm{LiO}^{\mathrm{t}} \mathrm{Bu}\right)-\mathrm{H}_{2} \mathrm{O}\right]+\left(\right.$ trimethyl phosphate - plasma $\left.\mathrm{N}_{2}\right)($ Kozen et al., 2015; Put et al., 2017) and (trisdimethylaminophosphorus $\left.-\mathrm{O}_{2}\right)+\left(\mathrm{LiO}^{\mathrm{t}} \mathrm{Bu}-\mathrm{NH}_{3}\right)($ Shibata, 2016). Despite of the subcycle strategy employed, LiPON reported in these work showed a high ionic conductivity of $\sim 10^{-7} \mathrm{~S} \mathrm{~cm}^{-1}$ at RT. By contrast, another work successfully deposited LiPON at $270-310^{\circ} \mathrm{C}$ by using just two precursors, lithium bis(trimethylsilyl)amide (LiHMDS) and diethyl phosphoramidate (DEPA) (Nisula et al., 2015). The growth rate of LiPON is $\sim 0.7 \AA /$ cycle, and the ionic conductivity of the LiPON deposited at $330^{\circ} \mathrm{C}$ reach as high as $6.6 \times 10^{-7} \mathrm{~S} \mathrm{~cm}^{-1}$ at $25^{\circ} \mathrm{C}$, highest one reported so far (Nisula et al., 2015). Later on, it is found that the combination of $\mathrm{LiO}^{\mathrm{t}} \mathrm{Bu}$ and DEPA also yielded self-limiting deposition of LiPON at temperatures of $250-300^{\circ} \mathrm{C}$ (Pearse et al., 2017a,b). Moreover, electrochemical analysis showed the good electrochemical stability of ALD-LiPON in a potential window of $0-5.3 \mathrm{~V}$ (vs. $\mathrm{Li} / \mathrm{Li}^{+}$). More importantly, the LiPON thin film exhibited excellent coverage and uniformity in 3D Si trend substrates (Pearse et al., 2017a,b). Furthermore, the ALD-LiPON has been validated to be functional in $2 \mathrm{D}$ solid-state batteries (Nisula and Karppinen, 2016; Pearse et al., 2017a,b; Put et al., 2017). For example, 2D solid-state batteries has been fabricated by using sputtered $\mathrm{LiCoO}_{2}$ as the cathode, ALD-LiPON as the electrolyte, and electron-beam-evaporated Si as the anode (Pearse et al., 2017a,b). The 2D $\mathrm{LiCoO}_{2} / \mathrm{LiPON} / \mathrm{Si}$ battery exhibited a cell capacity of $\sim 16 \mu \mathrm{Ah} \mathrm{cm}^{-2}$ at a current of $300 \mu \mathrm{Ah} \mathrm{cm}^{-2}$ for 150 cycles (Table 1). Therefore, ALD-LiPON by ALD (LiHMDS or $\mathrm{LiO}^{\mathrm{t}} \mathrm{Bu}-\mathrm{DEPA}$ ) holds great promise for

TABLE 1 | Solid-state battery configurations and areal capacities by atomic layer deposition (ALD) and other methods.

\begin{tabular}{|c|c|c|c|c|c|c|}
\hline Method & Type & $\begin{array}{l}\text { Battery } \\
\text { configuration }^{a}\end{array}$ & Substrate & Electrolyte & $\begin{array}{l}\text { Areal capacity } \\
\text { (electrode dimension) }\end{array}$ & Reference \\
\hline \multirow[t]{7}{*}{ ALD } & Hall cell & $\mathrm{CNTs} / \mathrm{FePO}_{4} / \mathrm{Li}_{3} \mathrm{PO}_{4}$ & 3D CNTs & $\mathrm{Li}_{3} \mathrm{PO}_{4}+$ liquid electrolyte & $\sim 40 \mu \mathrm{Ah} \mathrm{cm}^{-2}\left(0.25 \mathrm{~cm}^{2}\right)$ & Liu et al., 2016 \\
\hline & & $\mathrm{Pt} / \mathrm{TiO}_{2} / \mathrm{Li}_{3} \mathrm{PO}_{4}$ & 3D Si & $\mathrm{Li}_{3} \mathrm{PO}_{4}+$ liquid electrolyte & $\sim 370 \mu \mathrm{Ah} \mathrm{cm}^{-2}\left(0.785 \mathrm{~cm}^{2}\right)$ & Létiche et al., 2016 \\
\hline & & $\mathrm{Li}_{4} \mathrm{Ti}_{5} \mathrm{O}_{12} / \mathrm{LiPON} / \mathrm{Li}$ & $2 \mathrm{D} \mathrm{SiO}_{2}$ & $\mathrm{LiPON}$ & $\sim 0.3 \mathrm{Ah}_{\mathrm{cm}}^{-3}$ & Put et al., 2017 \\
\hline & & $\mathrm{SS} / \mathrm{Li}_{2} \mathrm{C}_{8} \mathrm{H}_{4} \mathrm{O}_{4} / \mathrm{LiPON}$ & $\begin{array}{l}\text { 2D stainless } \\
\text { steel (SS) }\end{array}$ & LiPON+liquid electrolyte & $\sim 7 \mu \mathrm{Ah} \mathrm{cm}^{-2}$ & $\begin{array}{l}\text { Nisula and } \\
\text { Karppinen, } 2016\end{array}$ \\
\hline & Full cell & $\mathrm{TiN}_{\mathrm{x}} / \mathrm{SnN}_{\mathrm{x}} / \mathrm{LiPON} / \mathrm{LiV}_{2} \mathrm{O}_{5} / \mathrm{Ru}$ & 3D Si & LiPON & $\sim 22 \mu \mathrm{Ah} \mathrm{cm}^{-2}$ & Pearse et al., 2017a,b \\
\hline & & $\mathrm{Cu} / \mathrm{Si} / \mathrm{Li}_{2} \mathrm{PO}_{2} \mathrm{~N} / \mathrm{LiV}_{2} \mathrm{O}_{5}$ & 2D Si & $\mathrm{Li}_{2} \mathrm{PO}_{2} \mathrm{~N}$ & $\sim 1.6 \mu \mathrm{Ah} \mathrm{cm}^{-2}$ & Pearse et al., 2017a,b \\
\hline & & $\mathrm{Cu} / \mathrm{Si} / \mathrm{Li}_{2} \mathrm{PO}_{2} \mathrm{~N} / \mathrm{LiCoO}{ }_{2} / \mathrm{Pt}$ & $2 \mathrm{D} \mathrm{Si}$ & $\mathrm{Li}_{2} \mathrm{PO}_{2} \mathrm{~N}$ & $\sim 16 \mu \mathrm{Ah} \mathrm{cm}^{-2}$ & \\
\hline Sputtering & Hall cell & $\mathrm{Li} / \mathrm{LiPON} / \mathrm{LiCoO}_{2}{ }^{\mathrm{b}}$ & 2D planar & LiPON & $\sim 65 \mu \mathrm{Ah} \mathrm{cm}^{-2}$ & Dudney, 2005 \\
\hline
\end{tabular}

${ }^{a}$ Battery configuration is writen in the order of conductive layer/anode/SSE/cathode/conductive layer, if applicable.

${ }^{b}$ Planar Li/LiPON/LiCoO ${ }_{2}$ fabricated by Sputtering is provided as a benchmark. 
3D solid-state battery application, considering its good ionic conductivity and straightforward ALD process.

\section{D SOLID-STATE BATTERIES BY ALD}

Although ALD has been widely used to design 3D structured anode or cathode in Li-ion batteries (Liu and Sun, 2015; Lu et al., 2017), there have been few reports about using ALD to fabricate 3D solid-state batteries due to the lack of suitable SSEs. With the recent success in glassy SSEs by ALD, several recent works have demonstrated the integration of 3D solid-state batteries in half- or full-cell configurations by ALD, as illustrated in Figure 1.

In a half-cell 3D configuration, one electrode material was first deposited on 3D substrates, and then coated with SSEs by ALD. Compared with only 3D electrodes (Cheah et al., 2009), the integration of SSEs on the 3D electrodes by ALD is one big step toward 3D solid-state batteries. Even though the testing of half-cell 3D electrodes with SSEs is still performed in liquid electrolytes, the functionality of SSEs could be confirmed in 3D configuration (Létiche et al., 2016; Liu et al., 2016). For example, Liu et al. had grown carbon nanotubes (CNTs) on carbon fibers as both the $3 \mathrm{D}$ substrate and current collector. Amorphous $\mathrm{FePO}_{4}$ was deposited on the 3D CNTs by ALD, forming a 3D hierarchical CNTs@FePO ${ }_{4}$ architecture, which was then coated with $\mathrm{Li}_{3} \mathrm{PO}_{4} \mathrm{SSE}$ by ALD at $250^{\circ} \mathrm{C}$ (Figure 1A) (Liu et al., 2016). The CNTs@FePO $@ \mathrm{Li}_{3} \mathrm{PO}_{4}$ electrode (surface area of $0.25 \mathrm{~cm}^{2}$ ) exhibited an areal capacity of $\sim 40 \mu \mathrm{Ah} \mathrm{cm}^{-2}, 20$ times higher than that on a planar substrate, in a liquid electrolyte $\left(1 \mathrm{M} \mathrm{LiPF}_{6}\right.$ in EC:DEC:EMC). The areal capacity could be controlled by adjusting ALD cycles, which are linearly dependent with $\mathrm{FePO}_{4}$ film thickness and loading. In another work, Manon et al. designed a $3 \mathrm{D}$ silicon wafer as a substrate with $\mathrm{Pt}$ as the current collector (Létiche et al., 2016). The half-cell solid-state battery (surface area $0.18 \mathrm{~cm}^{2}$ ) was integrated by step-wise deposition $\mathrm{TiO}_{2}$ and $\mathrm{Li}_{3} \mathrm{PO}_{4} \mathrm{SSE}$ by ALD (Figure 1B). The $3 \mathrm{D} \mathrm{TiO}_{2}$ electrodes with and without $\mathrm{Li}_{3} \mathrm{PO}_{4} \mathrm{SSE}$ showed typical redox peaks at 1.7 and

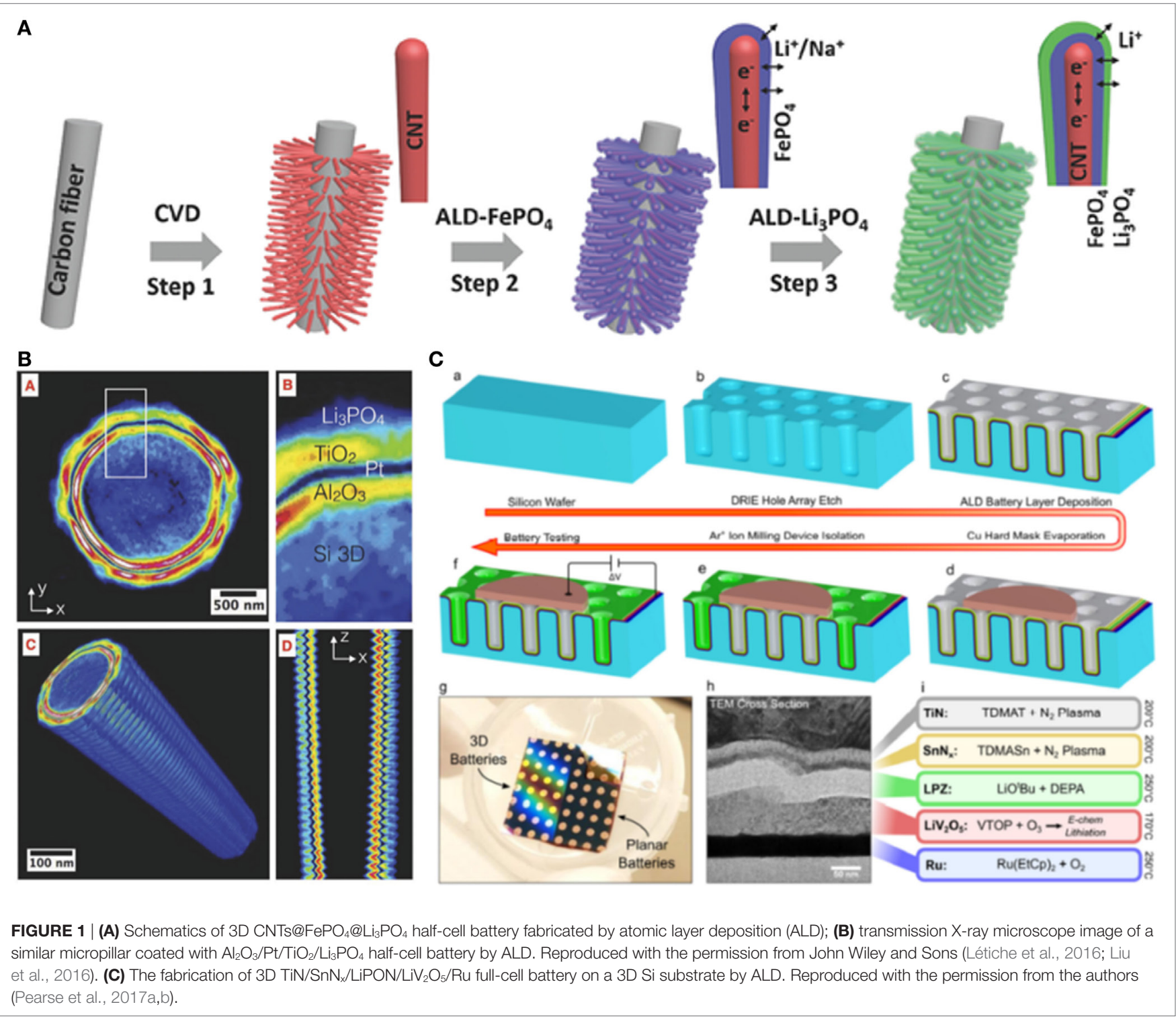


$2.1 \mathrm{~V}$ in a liquid electrolyte (1 M LiTFSI in EC:DEC), indicating the ionic conduction nature of $\mathrm{Li}_{3} \mathrm{PO}_{4}$. The $3 \mathrm{D} \mathrm{TiO}_{2}(55 \mathrm{~nm}) /$ $\mathrm{Li}_{3} \mathrm{PO}_{4}$ exhibited an areal capacity of $100 \mu \mathrm{Ah} \mathrm{cm} \mathrm{cm}^{-2}$ at $1 / 10^{\circ} \mathrm{C}$. When the thickness of $\mathrm{TiO}_{2}$ increased to $155 \mathrm{~nm}$, the areal capacity was enhanced to $370 \mu \mathrm{Ah} \mathrm{cm}^{-2}$, which is $\sim 100$ times higher than planar $\mathrm{TiO}_{2}$ electrode (Table 1). These work proven that ALD is indeed an effective approach to integrate SSE onto the anode or Cathode. The areal capacity of the 3D battery can be easily controlled by ALD cycles, which have linear relation with the thickness and loading of active materials. Nevertheless, significant technical challenges remain in the ALD deposition and electrochemical testing of full 3D solid-state batteries.

A full-cell 3D solid-state battery has been fabricated by ALD for the first time recently (Pearse et al., 2017a,b). In this work, the $3 \mathrm{D}$ solid-state battery was patterned on a 3D Si substrate by sequentially depositing $40 \mathrm{~nm} \mathrm{Ru}$ (cathode current collector), $70 \mathrm{~nm}$ prelithiated $\mathrm{V}_{2} \mathrm{O}_{5}$ (cathode), $50 \mathrm{~nm}$ LiPON (SSE), $10 \mathrm{~nm}$ $\mathrm{SnN}_{\mathrm{x}}$ (anode), and $25 \mathrm{~nm}$ TiN (anode current collector), finally covered in a layer of electron-beam evaporated $\mathrm{Cu}$ (Figure 1C). It should be pointed out that all the active components of the $3 \mathrm{D}$ solid-state battery were deposited by ALD in this work. During the first cycle, the 3D battery on the substrates with 10 and 4 aspect ratios delivered a capacity of $\sim 32$ and $12 \mu \mathrm{Ah} \mathrm{cm} \mathrm{cm}^{-2}$, respectively, which was 10.8 and 4.5 times relatively to the planar reference cell. Despite of irrversible capacity in the first few cycles, the 3D solid-state battery delivered a discharge capacity of $\sim 22 \mu \mathrm{Ah}$ $\mathrm{cm}^{-2}$ at 100 cycles at $100 \mu \mathrm{A} \mathrm{cm}$ cm $^{-2}$ (Table 1). This work is the first experimental proof of full-cell 3D solid-state battery realized by ALD, suggesting the feability and great potential of ALD for 3D battery device fabrication. Moreover, it is found that $40 \mathrm{~nm}$ LiPON was able to electrically isolate the anode and cathode in the $3 \mathrm{D}$ structure, indicating the complete coverage of ALD thin films on the $3 \mathrm{D}$ substrate. This finding is consistent with previous work in $\mathrm{ALD}-\mathrm{Li}_{5.1} \mathrm{TaO}_{z}$, in which the SSE was also found to be functional in $\sim 50 \mathrm{~nm}$ thickness (Liu et al., 2013). This is desirable for application because the reduced thickness of SSEs can decrease the cell impedance and ALD deposition time.

Table 1 lists both 2D and 3D solid-state batteries fabricated by ALD and their areal capacities, in comparison to a $2 \mathrm{D}$ thinfilm battery $\left(\mathrm{Li} / \mathrm{LiPON} / \mathrm{LiCoO}_{2}\right.$ ) fabricated by physical vapor deposition (Dudney, 2005). It is obvious that the areal capacity of 3D full-cell battery by ALD needs significant improvement to outperform the conventional $\mathrm{Li} / \mathrm{LiPON} / \mathrm{LiCoO}_{2} 2 \mathrm{D}$ thin-film battery (Dudney, 2005). Further capacity improvement can be achieved by using higher-asepct-ratio substrates, increasing elecrode film thickness, and optimizing the system (Létiche et al., 2016; Liu et al., 2016; Pearse et al., 2017a,b).

\section{SUMMARY AND PROSPECTIVE}

In this Mini Review, we discussed recent progress in the deposition of SSEs and the fabrication of 3D solid-state batteries via ALD approach. With success in ALD chemistry and process for LiPON and $\mathrm{Li}_{3} \mathrm{PO}_{4}, 3 \mathrm{D}$ solid-state batteries have been fabricated in half-cell or full-cell configurations by ALD. These works demonstrated the feasibility and potential of ALD technique in fabricating 3D solid-state batteries in a step-wise and wellcontrolled manner.

Regardless, further challenges remain in 3D solid-state batteries by ALD. First, the areal capacity of 3D solid-state batteries is to be further improved in order to outperform state-of-the-art 2D thin-film batteries. Future research should focus on using 3D substrates with higher aspect ratio, and thicker electrode thin films to enhance the areal capacity. Conformal deposition of thin films in high aspect ratio substrates (aspect ratio in excess of 1,000$)$ requires much longer exposure and purging time for precursors in order to achieve complete surface reactions and byproduct removals, which would significantly increase the ALD processing time (Elam et al., 2003). The ALD processing time could be further prolonged when thicker electrod thin films, in other words more ALD cycles, are required. Roll-toroll ALD or spatial ALD is a potential solution ro reduce the ALD processing time and improve deposition efficiency (Poodt et al., 2010). Second, simpler ALD process and chemistry, as for ALD-LiPON and $\mathrm{Li}_{3} \mathrm{PO}_{4}$, is required for Li-containing cathode, which contains three or more elements. The cathode materials developed by ALD so far involved complex surface chemisty, which is unsuitable for $3 \mathrm{D}$ battery integration from practical point of view. A fundamental obstacle is that most available ALD precursors could only deliver one metal element (such as oxides and sulfides) in one ALD cycle. As a result, more ALD precursors, cycles, and surface chemistry are needed to achieve mutil-element compounds. Advacement relies on the development of novel ALD precursors, such as double metal alkoxides (Mäntymäki et al., 2012), which could lead to two metal elements in one ALD cycles. The ALD-LiPON ( $\mathrm{LiO}^{t} \mathrm{Bu}-\mathrm{DEPA}$ ) is a good example of simplifying ALD surface chemisty, for which DEPA serves as both oxygen and nitrogen precursors. Third, the packaging and testing of $3 \mathrm{D}$ solid-state batteries needs more attentions. Although the recent work has reported a successful example (Pearse et al., 2017a,b), it requires multiple techniques in realizing the substrate conductive layers, and active materials. Finally yet importantly, the mechanical and chemical compatibilities of SSE with electrode thin films require further research attentions (Richards et al., 2016; Kerman et al., 2017). For example, stress/strain could develop in the electrode due to lithium intercalation/de-intercalation. Nevertheless, ALD has shown great promise in fabricating real $3 \mathrm{D}$ solid-state batteries on high-aspect-ratio substrates. It is expected that ALD will play a significant role in the development of practical 3D solid-state batteries for various applications, as such flexible electronics, MEMS.

\section{AUTHOR CONTRIBUTIONS}

All authors discussed the topics and contributed to the organization of this paper.

\section{FUNDING}

This work was sponsored by Nature Sciences and Engineering Research Council of Canada (NSERC) and the University of British Columbia (UBC). 


\section{REFERENCES}

Bates, J. B., Dudney, N. J., Neudecker, B., Ueda, A., and Evans, C. D. (2000). Thin-film lithium and lithium-ion batteries. Solid State Ionics. 135, 33-45. doi:10.1016/S0167-2738(00)00327-1

Cao, C., Li, Z. B., Wang, X. L., Zhao, X. B., and Han, W. Q. (2014). Recent advances in inorganic solid electrolytes for lithium batteries. Front. Energy Res. 2:25. doi:10.3389/fenrg.2014.00025

Cao, Y., Meng, X., and Elam, J. W. (2016). Atomic layer deposition of $\mathrm{Li}_{x} \mathrm{Al}_{y} \mathrm{~S}$ solid-state electrolytes for stabilizing lithium-metal anodes. ChemElectroChem 3, 858-863. doi:10.1002/celc.201600139

Cheah, S. K., Perre, E., Rooth, M., Fondell, M., Hårsta, A., Nyholm, L., et al. (2009). Self-supported three-dimensional nanoelectrodes for microbattery applications. Nano Lett. 9, 3230-3233. doi:10.1021/n19014843

Dudney, N. J. (2005). Solid-state thin-film rechargeable batteries. Mater. Sci. Eng. B 116, 245-249. doi:10.1016/j.mseb.2004.05.045

Elam, J. W., Routkevitch, D., Mardilovich, P. P., and George, S. M. (2003). Conformal coating on ultrahigh-aspect-ratio nanopores of anodic alumina by atomic layer deposition. Chem. Mater. 15, 3507-3517. doi:10.1021/cm0303080

George, S. M. (2010). Atomic layer deposition: an overview. Chem. Rev. 110, 111-131. doi:10.1021/cr900056b

Kazyak, E., Chen, K.-H., Wood, K. N., Davis, A. L., Thompson, T., Bielinski, A. R., et al. (2017). Atomic layer deposition of the solid electrolyte garnet $\mathrm{Li}_{7} \mathrm{La}_{3} \mathrm{Zr}_{2} \mathrm{O}_{12}$. Chem. Mater. 29, 3785-3792. doi:10.1021/acs.chemmater. $7 \mathrm{~b} 00944$

Kerman, K., Luntz, A., Viswanathan, V., Chiang, Y. M., and Chen, Z. (2017). Review-Practical challenges hindering the development of solid state $\mathrm{Li}$ ion batteries. J. Electrochem. Soc. 164, A1731-A1744. doi:10.1002/adma. 201000766

Knoops, H. C. M., Donders, M. E., van de Sanden, M. C. M., Notten, P. H. L., and Kessels, W. M. M. (2012). Atomic layer deposition for nanostructured Li-ion batteries. J. Vac. Sci. Technol. A 30, 010801. doi:10.1116/1.3660699

Kozen, A. C., Pearse, A. J., Lin, C.-F., Noked, M., and Rubloff, G. W. (2015). Atomic layer deposition of the solid electrolyte LiPON. Chem. Mater. 27, 5324-5331. doi:10.1021/acs.chemmater.5b01654

Létiche, M., Eustache, E., Freixas, J., Demortière, A., Andrade, V. D., Morgenroth, L., et al. (2016). Atomic layer deposition of functional layers for on chip 3D Li-ion all solid state microbattery. Adv. Energy Mater. 7, 1601402. doi:10.1002/ aenm.201601402

Liu, J., Banis, M. N., Li, X., Lushington, A., Cai, M., Li, R., et al. (2013). Atomic layer deposition of lithium tantalate solid-state electrolytes. J. Phys. Chem. C 117, 20260-20267. doi:10.1021/jp4063302

Liu, J., and Sun, X. (2015). Elegant design of electrode and electrode/electrolyte interface in lithium-ion batteries by atomic layer deposition. Nanotechnology 26, 024001. doi:10.1088/0957-4484/26/2/024001

Liu, J., Wang, B., Sun, Q., Li, R., Sham, T.-K., and Sun, X. (2016). Atomic layer deposition of hierarchical CNTs@FePO${ }_{4}$ architecture as a 3D electrode for lithium-ion and sodium-ion batteries. Adv. Mater. Interfaces 3, 1600468. doi:10.1002/admi.201600468

Long, J. W., Dunn, B., Rolison, D. R., and White, H. S. (2004). Three-dimensional battery architectures. Chem. Rev. 104, 4463-2292. doi:10.1021/cr0207401
Lu, W., Liang, L., Sun, X., Sun, X., Wu, C., Hou, L., et al. (2017). Recent progresses and development of advanced atomic layer deposition towards highperformance Li-ion batteries. Nanomaterials 7, 325. doi:10.3390/nano7100325

Mäntymäki, M., Ritala, M., and Leskelä, M. (2012). Double metal alkoxides of lithium: synthesis, structure and applications in materials chemistry. Coord. Chem. Rev. 256, 854-877. doi:10.1016/j.ccr.2011.11.015s

Nisula, M., and Karppinen, M. (2016). Atomic/molecular layer deposition of lithium terephthalate thin films as high rate capability Li-ion battery anodes. Nano Lett. 16, 1276-1281. doi:10.1021/acs.nanolett.5b04604

Nisula, M., Shindo, Y., Koga, H., and Karppinen, M. (2015). Atomic layer deposition of lithium phosphorus oxynitride. Chem. Mater. 27, 6987-6993. doi:10.1021/ acs.chemmater.5b02199

Oudenhoven, J. F. M., Baggetto, L., and Notten, P. H. L. (2011). All-solid-state lithium-ion microbatteries: a review of various three-dimensional concepts. Adv. Energy Mater. 1, 10-33. doi:10.1002/aenm.201000002

Pearse, A. J., Schmitt, T. E., Fuller, E. J., El-Gabaly, F., Lin, C.-F., Gerasopoulos, K., et al. (2017a). Nanoscale solid state batteries enabled by thermal atomic layer deposition of a lithium polyphosphazene solid state electrolyte. Chem. Mater. 29, 3740-3753. doi:10.1021/acs.chemmater.7b00805

Pearse, A. J., Schmitt, T. E., Sahadeo, E., Stewart, D., Kozen, A. C., Gerasopoulos, K., et al. (2017b). Three-Dimensional Solid-State Lithium-Ion Batteries Fabricated via Conformal Vapor-Phase Chemistry. arXiv:1709.02918.

Poodt, P., Lankhorst, A., Roozeboom, F., Spee, K., Mass, D., and Vermeer, A. (2010). High-speed spatial atomic-layer deposition of aluminum oxide layers for solar cell passivation. Adv. Mater. 22, 3564-3567. doi:10.1002/adma.201000766

Put, B., Mees, M. J., Hornsveld, N., Sepúlveda, A., Vereecken, P. M., Kessels, W. M. M., et al. (2017). Plasma-assisted ALD of LiPO(N) for solid-state batteries. ECS Trans. 75, 61-69. doi:10.1149/07520.0061ecst

Richards, W. D., Miara, L. J., Wang, Y., Kim, J. C., and Ceder, G. (2016). Interface stability in solid-state batteries. Chem. Mater. 28, 266-273. doi:10.1021/acs. chemmater.5b04082

Roberts, M., Johns, P., Owen, J., Brandell, D., Edstrom, K., Enany, G. E., et al. (2011). 3D lithium ion batteries-from fundamentals to fabrication. J. Mater. Chem. 21, 9876-9890. doi:10.1039/C0JM04396F

Shibata, S. (2016). Thermal atomic layer deposition of lithium phosphorus oxynitride as a thin-film solid electrolyte. J. Electrochem. Soc. 163, A2555-A2562. doi:10.1149/2.0371613jes

Xie, J., Sendek, A. D., Cubuk, E. D., Zhang, X., Lu, Z., Gong, Y., et al. (2017). Atomic layer deposition of stable $\mathrm{LiAlF}_{4}$ lithium ion conductive interfacial layer for stable cathode cycling. ACS Nano 11, 7019-7027. doi:10.1021/acsnano.7b02561

Conflict of Interest Statement: The authors declare that the research was conducted in the absence of any commercial or financial relationships that could be construed as a potential conflict of interest.

Copyright $\odot 2018 \mathrm{Liu}, \mathrm{Zhu}$ and Shiraz. This is an open-access article distributed under the terms of the Creative Commons Attribution License (CC BY). The use, distribution or reproduction in other forums is permitted, provided the original author(s) and the copyright owner are credited and that the original publication in this journal is cited, in accordance with accepted academic practice. No use, distribution or reproduction is permitted which does not comply with these terms. 